\title{
Innovation of risk analytics for technology and society
}

\author{
Zachary A. Collier ${ }^{1}$. James H. Lambert ${ }^{2} \cdot$ Igor Linkov $^{3}$
}

Published online: 16 November 2019

(c) Springer Science+Business Media, LLC, part of Springer Nature 2019

In this issue of Environment Systems \& Decisions, the articles present applications of analytics under conditions of uncertainty brought about by technological and environmental change. The common feature of the papers featured in this issue is the novel application of risk management and quantitative decision making techniques to address issues of social concern. Applications at the intersection of technology and society, including automated vehicles, geoengineering, and sustainable building construction are discussed in this issue. Papers in this issue present modeling and management strategies for systems that integrate environmental, economic, and social perspectives, and range from climate change adaptation to sports. This transdisciplinary intersection of modeling and application domains is an important area of research served by Environment Systems \& Decisions.

First, Grieger et al. (2019) discuss the technological and societal implications of stratospheric aerosol injection as a means of mitigating impacts of climate change. Through a lens of emerging risk governance, the authors explore the implications of this technology in terms of costs, benefits, and risks. Pütz et al. (2019) examine the rapidly developing field of automated vehicles with respect to risk management and insurance coverage. The authors find that radical technological changes in transportation will have impacts for the insurance industry and for regulatory bodies. Allred and Gary (2019) conduct a survey of land-owners to uncover the motivations and drivers of pro-environmental behavior.

Zachary A. Collier

zac4nf@virginia.edu

James H. Lambert

lambert@virginia.edu

Igor Linkov

igor.linkov@usace.army.mil

1 Collier Research Systems, Barboursville, VA, USA

2 University of Virginia, Charlottesville, VA, USA

3 US Army Engineer Research \& Development Center, Concord, MA, USA
They find a number of motivational factors influencing decision making with implication for flood risk reduction and land management. Kjelland et al. (2019) demonstrate a multi-compartment simulation model of water levels in the Saltan Sea. Comparing 34 scenarios through the year 2024, the authors derive insights into water management strategies. Sanchez et al. (2019) investigate the economic and environmental impacts of adaptive reuse strategies in buildings. Using a courthouse as a case study, the authors conclude that adaptive reuse of a building structure can provide environmental benefits and reduce construction costs. Mirzaee et al. (2019) compare two multi-criteria decision analysis techniques, SMART and PAPRIKA, in the context of sustainable building design. They find that while the decision makers reported feeling that both methods accurately captured their preferences, the methodological techniques produce different results. Keenan and Gumber (2019) implement a portfolio model to identify the potential challenged and benefits of creating a state climate adaptation trust fund. Using California's cap and trade revenue as an example, the authors estimate the size and performance of such a fund, and discuss the challenges and opportunities associated with its implementation and management. Payyappalli and Zhuang (2019) develop an integer programming model to identify the optimal transfer of players between soccer teams which maximize each club's utility. The model is demonstrated for the Premier League, but can accommodate data for any club in any country.

The Editorial Board invites submissions from researchers on topics related to the application of novel methodologies to pressing societal, technological, and environmental issues. Review papers and shorter "perspectives" articles are welcome. For inquiries regarding editing a special issue, please contact the Editors in Chief. 


\section{References}

Allred S, Gary G (2019) Riparian landowner decision-making in the context of flooding: an application of the theory of planned behavior. Environ Syst Decis 39(4):1-13. https://doi.org/10.1007/s1066 9-019-09735-1

Grieger KD, Felgenhauer T, Renn O, Wiener J, Borsuk M (2019) Emerging risk governance for stratospheric aerosol injection as a climate management technology. Environ Syst Decis 39(4):1-12. https://doi.org/10.1007/s10669-019-09730-6

Keenan JM, Gumber A (2019) California climate adaptation trust fund: exploring the leveraging of cap-and-trade proceeds. Environ Syst Decis 39(4):1-12. https://doi.org/10.1007/s10669-019-09740-4

Kjelland ME, Cathcart RB, Swannack TM (2019) In silico macroimagineering of Salton Sea alternative futures under climate uncertainty and water transfer considerations. Environ Syst Decis 39(4):1-10. https://doi.org/10.1007/s10669-019-09719-1
Mirzaee S, Fannon D, Ruth M (2019) A comparison of preference elicitation methods for multi-criteria design decisions about resilient and sustainable buildings. Environ Syst Decis 39(4):1-15. https ://doi.org/10.1007/s10669-019-09726-2

Payyappalli VM, Zhuang J (2019) A data-driven integer programming model for soccer clubs' decision making on player transfers. Environ Syst Decis 39(4):1-16. https://doi.org/10.1007/s10669-01909721-7

Pütz F, Murphy F, Mullins M (2019) Driving to a future without accidents? Connected automated vehicles' impact on accident frequency and motor insurance risk. Environ Syst Decis 39(4):1-13. https://doi.org/10.1007/s10669-019-09739-x

Sanchez B, Esfahani ME, Haas C (2019) A methodology to analyze the net environmental impacts and building's cost performance of an adaptive reuse project: a case study of the Waterloo County Courthouse renovations. Environ Syst Decis 39(4):1-20. https:// doi.org/10.1007/s10669-019-09734-2 